\title{
Responses of leaf traits to low temperature in an evergreen oak at its upper limit
}

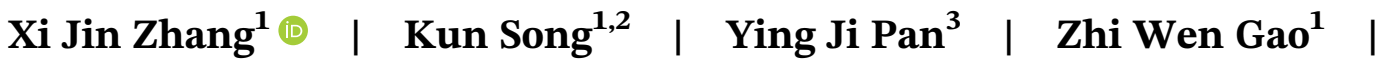 \\ Fa Guang Pu ${ }^{4}$ | Jia Hui Lu ${ }^{1}$ | Kan Kan Shang, | Liang Jun Da ${ }^{1,2}$ | \\ Ellen Cieraad ${ }^{3}$
}

\footnotetext{
${ }^{1}$ Tiantong National Forest Ecosystem Observation and Research Station, Shanghai Key Lab for Urban Ecological Processes and Eco-Restoration, School of Ecological and Environmental Sciences, East China Normal University, Shanghai, China

${ }^{2}$ Institute of Eco-Chongming, Shanghai, China

${ }^{3}$ Institute of Environmental Sciences (CML), Leiden University, Leiden, The Netherlands

${ }^{4}$ Anhui Dabie Mountain Forest Ecosystem National Observation Station, Jinzhai, China

${ }^{5}$ Shanghai Chenshan Plant Science Research Center, The Chinese Academy of Science, Shanghai Chenshan Botanical Garden, Shanghai, China
}

\section{Correspondence}

Kun Song, Tiantong National Forest Ecosystem Observation and Research Station, Shanghai Key Lab for Urban Ecological Processes and Eco-Restoration, School of Ecological and Environmental Sciences, East China Normal University, Shanghai, China; Institute of Eco-

Chongming, Shanghai, China.

Email: ksong@des.ecnu.edu.cn

Liang Jun Da, Shanghai Key Lab for Urban Ecological Processes and EcoRestoration, School of Ecological and Environmental Sciences, East China Normal University, Shanghai, China; Institute of Eco-Chongming, Shanghai, China.

Email: ljda@des.ecnu.edu.cn

\section{Funding information}

National Natural Science Foundation of China, Grant/Award Numbers: 31600343, 31670438, 31500355

\begin{abstract}
Low temperature is a major driver of the upper distributional limits of subtropical evergreen broadleaved forests in East Asia. The eco-physiology of evergreen broadleaved trees at the upper limits could respond to both lower winter temperature and lower averaged annual temperature that covary with elevation. To analyze these responses, we assessed the variations in leaf chemical traits of Cyclobalanopsis gracilis with seasonality and along elevation in the ecotone from subtropical to temperate climate, and analyzed the relationships between traits of mature leaves and temperature. The study showed that the mass-based nonstructural carbohydrate (NSC) content reached the highest level across elevations during winter; however, the winter NSC content did not differ between elevations. For mature leaves, leaf dry mass per area (LMA) tended to be higher approaching the upper limit. The leaf carbon to phosphorus ratio $(\mathrm{C} / \mathrm{P})$ showed an increasing trend with decreasing temperature, as did leaf carbon to nitrogen ratio $(\mathrm{C} / \mathrm{N})$ to some extent. The mass-based $\mathrm{P}$ content showed a decreasing trend approaching the upper limit, whereas area-based $\mathrm{P}$ content showed no significant variation. Our main results indicate that leaf NSC content is highest at all elevations in winter, and individuals at high elevations have high LMA and high nutrient use efficiency. The results suggest that for $C$. gracilis, an increasing leaf NSC results in a baseline protection to cope with cold in winter, which, at higher elevations is supplemented with increasing LMA and nutrient use efficiency to cope with associated low-temperature stress.
\end{abstract}

\section{K E Y W O R D S}

elevation, leaf mass per area, nonstructural carbohydrates, seasonality, stoichiometry 


\section{1 | INTRODUCTION}

The leading edge of biogeographic distribution (i.e., upper and northern limit) of many forests are associated with low temperature. A species approaching its leading edge can respond to low temperature by morphological and physiological changes (Körner, 2012; Midolo, De Frenne, Hölzel, \& Wellstein, 2019). In contrast to the well-studied temperate forests (Körner, 2003a; Mayor et al., 2017), the leading edges of subtropical forest are understudied. The subtropical monsoon climatic conditions of East Asia have given rise to evergreen broadleaved forests (EBLF) (Song, 1988). Although the distributional limits of EBLF are associated with low temperature (Da et al., 2009; Yim \& Kira, 1975), the adaptive strategies employed by trees to cope with low temperature approaching the distributional limits are yet not fully understood. The plant leaf is an organ exposed to and sensitive to the environment and it exhibits morphological and stoichiometric plasticity in adaptation to abiotic stresses (Klich, 2000; Xu, Guo, Xu, Wei, \& Wang, 2009; Zhang, Zhang, Slik, \& Cao, 2012). Considering the leaf eco-physiology of evergreen broadleaved species could be influenced by the interactions between seasonal variations and elevational gradients (Rathore, Thakur, \& Chawla, 2018), studying both seasonal and elevational gradients is necessary to understand plant adaptive strategies. Although some studies exist on elevational or seasonal effects on leaf traits of broadleaved evergreen species (Li, Zhang, Liu, Luukkanen, \& Berninger, 2006; Palacio et al., 2018; Vitousek, Field, \& Matson, 1990), the seasonal variations of leaf traits coupled with an elevational gradient are understudied (Rathore et al., 2018).

While winter of subtropical regions are milder compared with temperate regions, subtropical forests still need to cope with considerable seasonal changes in temperature, especially approaching their northern limit where the subtropical climate changes to a temperate climate. In winter, evergreen broadleaved trees increase the foliar concentration of nonstructural carbohydrate (NSC) (Körner, 2003b; Zhu, Cao, Wang, Xiao, \& Li, 2012). The concentration of NSC is related to the maximum cold tolerance as it prevents intracellular freezing via hydrolysis to soluble sugar (Morin et al., 2007). However, enhancing cold tolerance solely via osmotic adjustment would not be sufficient to resist temperatures colder than a few degrees below zero, since most plants would freeze at a temperature of $-1.8^{\circ} \mathrm{C}$ if under sole protection of osmotic adjustment (Körner, 2012). Trees at their upper distributional limits suffer from lower winter temperature and a longer duration of winter compared with those at low elevation. Therefore, the individuals at high elevation may employ other adaptive strategies to cope with the colder temperature. Of these plant strategies to survive below the solute freezing point, extracellular ice formation is the most common (Körner, 2012). The rate of extracellular ice formation and thawing can be further reduced through an increase in leaf thickness (Ball et al., 2002; Niinemets, 2016). Thicker leaves can be achieved through an increase in the number of cell layers, an increase in the thickness of cell layers (Atkin, Botman, \& Lambers, 1996; Körner, Neumayer, Menendez-Riedl, \& SmeetsScheel, 1989; Woodward, 1979), or via a thickening of the cell walls, a characteristic of leaves growing in cold climates (Kubacka-Zębalska \& Kacperska, 1999; Stefanowska, Kuraś, Kubacka-Zebalska, \& Kacperska, 1999). Any such changes would contribute to a greater leaf dry mass per area (LMA) (Mediavilla, GallardoLópez, González-Zurdo, \& Escudero, 2012). LMA of new leaves of subtropical evergreen broadleaved trees are more stable in the second half than the first half of the year (Xue et al., 2012). Consequently, we hypothesize two important adaptive strategies to cope with winter low temperature for evergreen broadleaved trees. First, massbased leaf NSC content of the subtropical evergreen broadleaved tree species would be higher toward winter across elevations, and accumulates more NSC in winter at their upper limits compared with low elevations. Second, the trees at the upper limits have higher LMA of mature leaves compared with low elevations.

The lower annual temperature and shorter growing season associated with higher elevation provide a more stressful environment, with which the leaves of evergreen broadleaf trees, and important processes like photosynthesis, need to cope. In addition to an increased LMA, higher foliar contents of nitrogen $(\mathrm{N})$ and phosphorus $(\mathrm{P})$ are generally regarded as adaptations to low temperature (Oleksyn, Modrzýnski, Tjoelker, Reich, \& Karolewski, 1998; Weih \& Karlsson, 2001). However, recent metaanalyses showed that LMA increased with increasing elevation at the intraspecific level, mass-based leaf $\mathrm{N}$ and $\mathrm{P}$ content may not vary systematically with increasing elevation (Midolo et al., 2019; Read, Moorhead, Swenson, Bailey, \& Sanders, 2014). Previous studies showed no significant differences in the area-based photosynthetic capacity along elevations for evergreen broadleaved tree species, while decreasing trends were observed with increasing elevation when considering photosynthesis on a mass basis (Chai et al., 2015; Cordell, Goldstein, Meinzer, \& Handley, 1999). Since mass-based leaf N and $\mathrm{P}$ content shows stronger positive associations with photosynthesis capacity than consideration on area basis (Wright et al., 2004), we expected a decreasing trend in mass-based leaf $\mathrm{N}$ and $\mathrm{P}$ content in evergreen broadleaf foliage with increasing elevation, but no trend in areabased leaf $\mathrm{N}$ and $\mathrm{P}$ content. 
Cyclobalanopsis gracilis (Fagaceae) is a dominant evergreen broadleaved canopy tree that reaches both the northern and upper distributional limits of EBLF in eastern China (Da et al., 2009; Fang, Wang, \& Tang, 2011). Leaves of $C$. gracilis were analyzed for LMA, for chemical traits such as leaf $\mathrm{N}$ content, $\mathrm{P}$ content, carbon content (C) and their stoichiometric ratio $(\mathrm{N} / \mathrm{P}, \mathrm{C} / \mathrm{N}$ and $\mathrm{C} / \mathrm{P})$, as well as NSC content. We investigated seasonal variations in leaf chemical traits along elevational gradients and the responses of mature leaf traits to climate initiated temperature gradients covarying with elevation to test the following three hypotheses: (a) The foliar NSC content in winter reaches the highest value across the seasons and is higher at the upper limits than at the lower elevations. (b) LMA is higher at high elevation compared with low elevation. (c) Mass-based N and P content decreases with increasing elevation while no trends are expected in areabased $\mathrm{N}$ and $\mathrm{P}$ content. We analyzed the three hypotheses to elucidate the responses of leaf traits to low temperature for $C$. gracilis at its upper limit.

\section{2 | MATERIALS AND METHODS}

\section{1 | Study area and plant sampling}

The current study was conducted in Tianma National Nature Reserve, located at the junction of Anhui, Henan and Hubei provinces $\left(115^{\circ} 20^{\prime}-115^{\circ} 50^{\prime} \mathrm{E}, 30^{\circ} 10^{\prime}-31^{\circ} 20^{\prime} \mathrm{N}\right)$, China (Figure 1). The region is characterized by a subtropical moist monsoon climate, with mean annual temperature of $13.8^{\circ} \mathrm{C}$. Extreme temperatures of 38.1 and $-23^{\circ} \mathrm{C}$ have been recorded in July and January, respectively. The mean annual precipitation is $1,489 \mathrm{~mm}$, with most precipitation from May to September. This region is a transition area from EBLF to deciduous broadleaved forest (Song, Kohyama, \& Da, 2014) and consists of a mixture of the two types of forests (Song \& Da, 2016).

We selected one transect in each of the two mountain ranges, named Tiantangzhai (TTZ) and Mazongling (MZL), respectively. The two mountain ranges make up the core area of the nature reserve. From the low limit $(\sim 740 \mathrm{~m})$ to the upper limit $(\sim 1,200 \mathrm{~m})$ of $C$. gracilis along each transect, we set up sample plots at three elevations (low, medium and high) in areas where adult $C$. gracilis were dominant or at high density, and which were at least $125 \mathrm{~m}$ and at most $275 \mathrm{~m}$ apart by elevation (see Table 1 for details of elevation). The sample plot area ranged from 400 to $525 \mathrm{~m}^{2}$. Along the two elevational transects, we measured environmental conditions and collected $C$. gracilis leaf material in each sample plot.

The air temperature of each sample plot was recorded using a HOBO Pro data logger (U23-001 Pro v2; Onset Computer Corporation, Bourne, MA) which was mounted about $1.5 \mathrm{~m}$ above ground on a selected adult $C$. gracilis to avoid direct sunlight all through the year. Temperature was logged every hour for 1 year (from 11/2016 to $10 / 2017)$. Data were summarized to calculate the mean and extreme monthly temperatures, warmth and coldness indices, and days of frost in the year. In August 2018 , five soil samples ( $20 \mathrm{~cm}$ beneath ground) were taken with a small spade from randomly chosen spots in each plot after the litter layer being removed. The five samples per plot were combined and soil $\mathrm{pH}$ and nutrient $115^{\circ} 18^{\prime} \mathrm{E}$

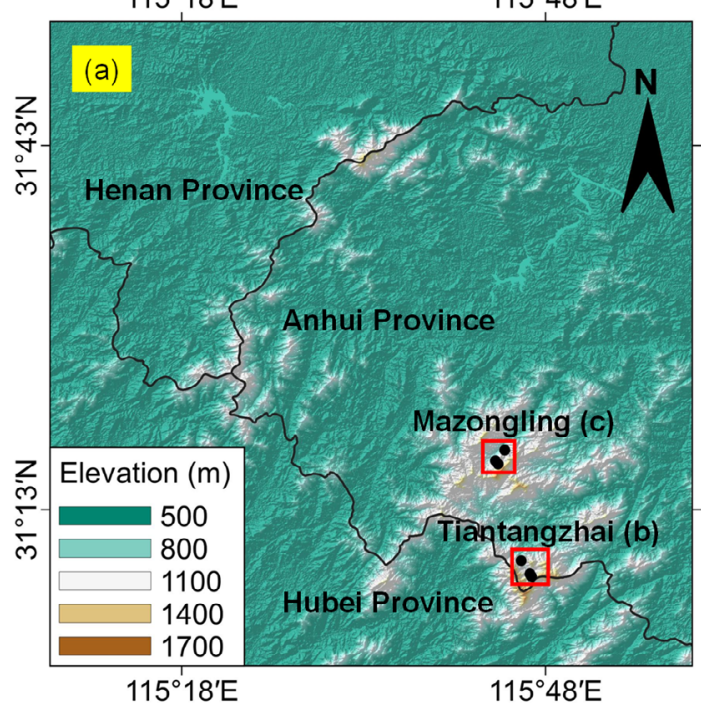

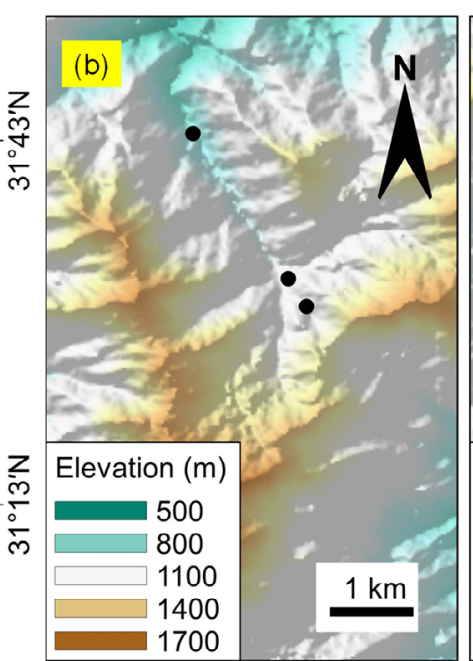

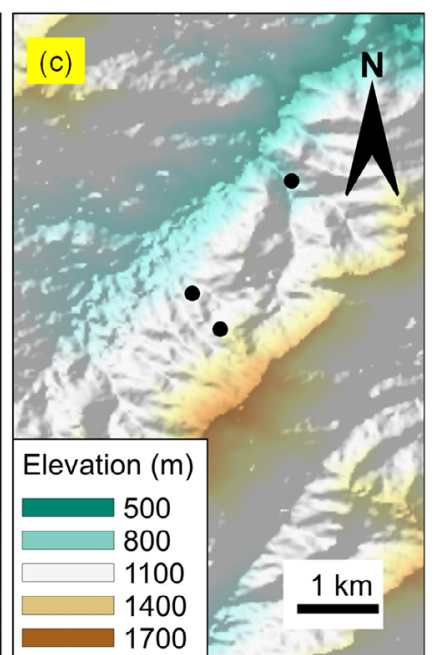

FI G U RE 1 Location of study area and sample plots. (a) The location of two transects (Mazongling transect and Tiantangzhai transect) and ( $\mathrm{b}$ and $\mathrm{c}$ ) the sample plots along the Tiantangzhai transect and Mazongling transect, respectively [Color figure can be viewed at wileyonlinelibrary.com] 
T A B L E 1 Summary of climatic and soil environmental measurements (mean values) along Tiantangzhai and Mazongling transects

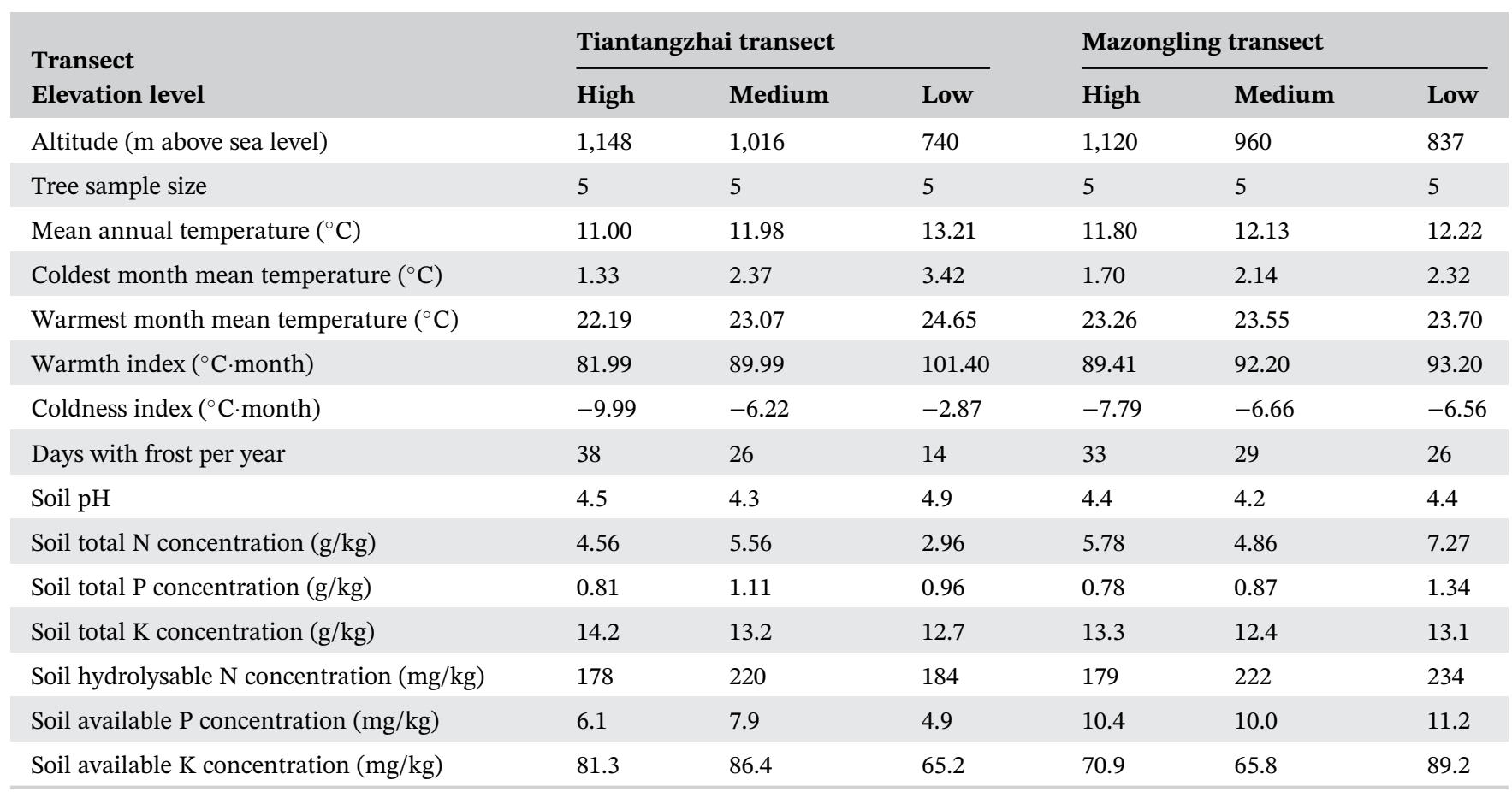

concentrations (total $\mathrm{N}, \mathrm{P}, \mathrm{K}$, hydrolysable $\mathrm{N}$, and available $\mathrm{P}$ and available $\mathrm{K}$; see Table 1) were determined following the protocol of Chinese Forest Soil Test Standards (LY/T 1239-1999, LY/T 1228-2015, LY/T 1232-2015 and $\mathrm{LY} / \mathrm{T}$ 1234-2015).

Along the two elevational transects, we sampled leaf material four times, according to the seasonal variation and phenological stage of C. gracilis: (a) October 2016 (the end of growing season); (b) February 2017 (during winter dormancy); (c) May 2017 (the early time of growing season); (d) August 2017 (the fast-growing stage). Preliminary observations on mature individuals of $C$. gracilis in summer showed that leaves on the leading twigs (i.e., shoot between the apex of branch and the first bud scale scar, considered current-year leaves) account for more than $75 \%$ of the leaves in crowns (Figure S1). Thus, except for spring collection at the high elevation in TTZ, five leading twigs with leaves were collected from each of five healthy undamaged adult trees at each elevation to avoid comparing biases due to mixed leaves cohorts. To reduce the confounding effect of sunlight on leaf traits, twigs were selected in peripheral parts of the crown. At the high elevation in TTZ (upper limit of $C$. gracilis) budburst was delayed in spring, so during collection most twigs were just at the start of budburst and the others were at the start of leaf-expansion with small and young current-year leaves. At this time of year, 1-yearold leaf cohorts therefore presumably provide a major contribution to net primary production in spring. At high elevation in TTZ in spring we therefore collected both current-year and 1-year-old leaf cohorts and these were analyzed separately. Leaves were scanned and then killed in a microwave oven within $12 \mathrm{hr}$ after sampling (Shi, Körner, \& Hoch, 2010). Then, the samples were dried to constant mass at $65^{\circ} \mathrm{C}$ for leaf dry weight measurements.

\subsection{Measurements of leaf traits}

Leaf trait measurements included one morphological trait (LMA) and several chemical composition traits (mass-based nitrogen, phosphorus, carbon and NSCs content). Leaf morphological traits were only measured for leaves collected in August, when leaves had fully expanded to a consistent leaf area (Nitta \& Ohsawa, 1997). Leaf area was measured using "Image J" software (Schneider, Rasband, \& Eliceiri, 2012) on scanned images. LMA was calculated as total dry mass divided by the total area of the leaf.

Dried leaves were crushed into a fine powder after being weighed and then processed for analysis of the total nitrogen and total carbon (mass-based) using an elemental analyzer (vario MICRO cube; Elementar, Hanau, Germany). Leaf phosphorous concentration (mass-based) was estimated colorimetrically using a discrete analyzer (SmartChem 200, Westco Scientific Instruments, Brookfield, CT). 
NSC was estimated following an improved colorimetric method (Buysse \& Merckx, 1993). The soluble sugars were extracted by weighing about $40 \mathrm{mg}$ of leaf powder into a centrifuge tube and recording the weight, adding $10 \mathrm{ml}$ of $80 \%$ ethanol into tubes and incubating the closed tubes in a water bath for $60 \mathrm{~min}$ at $80^{\circ} \mathrm{C}$ followed by centrifuging at $4000 \mathrm{rpm}$ for $15 \mathrm{~min}$. The supernatant was transferred to $100 \mathrm{ml}$ volumetric flasks. Five milliliters of $80 \%$ ethanol was then added to the tubes. The processes of water bath, centrifuging and supernatant collection were then repeated. The total volume of the combined supernatant was adjusted to $100 \mathrm{ml}$ for later measurement.

Starch remaining in the undissolved pellet after drying the residuals in the tubes were hydrolyzed in a boiling 3\% $\mathrm{HCl}$ solution for $3 \mathrm{hr}$. And then after filtering the solution into a new batch of $100 \mathrm{ml}$ volumetric flasks, the total volume of the solution was adjusted to $100 \mathrm{ml}$ to be measured later.

In a glass tube, $1 \mathrm{ml}$ of the extracting solution and 1 $\mathrm{ml} 28 \%$ phenol solution (84 $\mathrm{g}$ phenol adding $80 \%$ ethanol to $300 \mathrm{~g}$ ) were added. Immediately afterwards, $5 \mathrm{ml}$ concentrated sulfuric acid was added. The tube was shaken for $1 \mathrm{~min}$ and rested for at least $15 \mathrm{~min}$ before absorbance was measured at $490 \mathrm{~nm}$ (UV-9600). The standard solution was sucrose. The sum of soluble sugar and starch concentration was referred to as total NSCs.

The area basis of summer leaf chemical traits were calculated as mass basis of the traits multiplied by LMA.

\section{3 | Data analysis}

For each transect, two-way ANOVA was employed to assess the effects of seasonality and elevation, as well as their interaction, on leaf chemical traits. Elevational effects on leaf chemical traits within each season were tested by one-way ANOVA. A $t$-test was used to test for differences between the current-year leaves and 1-yearold leaves at high elevation in the TTZ transect in spring. Log transformation was applied to some of the data to comply to the normal distribution assumption. To avoid possible differences in leaf traits among the elevations due to the different development state of the leaves, only leaf traits measured in summer were used to further investigate the response of leaf traits to environments that covaried with elevations. Since only temperaturerelated variables showed significant correlations with the elevational gradient among the three types of environmental variables (i.e., air temperature-related, air humidity-related and soil nutrients-related variables) (Table S1), the dominant environmental factor along the elevational gradient in the study region was temperature. Because the upper distributional limits of EBLF in East Asia corresponded to a mean temperature during the coldest month that were reported in many studies (Da et al., 2009; Ohsawa, 1990), the coldest month mean temperature (CMT) gradient was employed as the environmental gradient in this study. We use ordinary linear regression to assess the relationship between CMT and leaf traits. Because the lowest sites had much higher CMT than the other sites, which may result in a nonrobust regression, the effects of temperature gradient on leaf traits were also tested by one-way ANOVA. The differences between any two of temperature gradients were tested with HSD test because the variances among elevations were equal. All analyses were performed with $\mathrm{R}$ software ( $\mathrm{R}$ version 3.6.0). Ordinary linear regression and $t$-test were performed with the $l m$ and t.test functions, respectively, in the base package. One-way and two-way ANOVAs were performed using the ANOVA function in car package 3.03 (Fox \& Weisberg, 2019) and HSD test was made using the HSD.test function in agricolae package 1.3-1 (Mendiburu, 2019).

\section{3 | RESULTS}

\section{1 | Seasonal variations in leaf chemical traits}

Seasonality had a significant effect on all leaf chemical traits in both transects. At the TTZ transect, there was a significant interaction effect of elevation and seasonality for four of the seven leaf chemical traits. For the TTZ transect, mass-based leaf $\mathrm{N}$ and $\mathrm{P}$ content reached the highest level in spring (May) (Figure 2a,c). Mass-based leaf $\mathrm{C}$ content reached the highest levels in summer (August) (Figure 2e). The stoichiometric nutrient ratios $(\mathrm{N} / \mathrm{P}, \mathrm{C} / \mathrm{N}$ and $\mathrm{C} / \mathrm{P})$ generally reached minimum levels during spring (Figure 3a,c,e). The mass-based leaf NSC content increased from autumn to winter, and was at higher level during winter than over the growing season. The differences of mass-based leaf NSC content among elevations were only significant in spring for current-year leaves (Figure 2g). In spring, the differences in each leaf chemical trait between the currentyear leaves and 1-year-old leaves were significant at the high elevation in TTZ transect. For MZL transect, the general trends of seasonal variation of leaf chemical traits were similar to those in TTZ transect (Figures 2 and 3, right panel). However, few leaf chemical traits showed significant differences along elevational gradient in the same season (Figures 2 and 3), and no significant interactions between elevation and seasonality were found (Table 2). 
TTZ
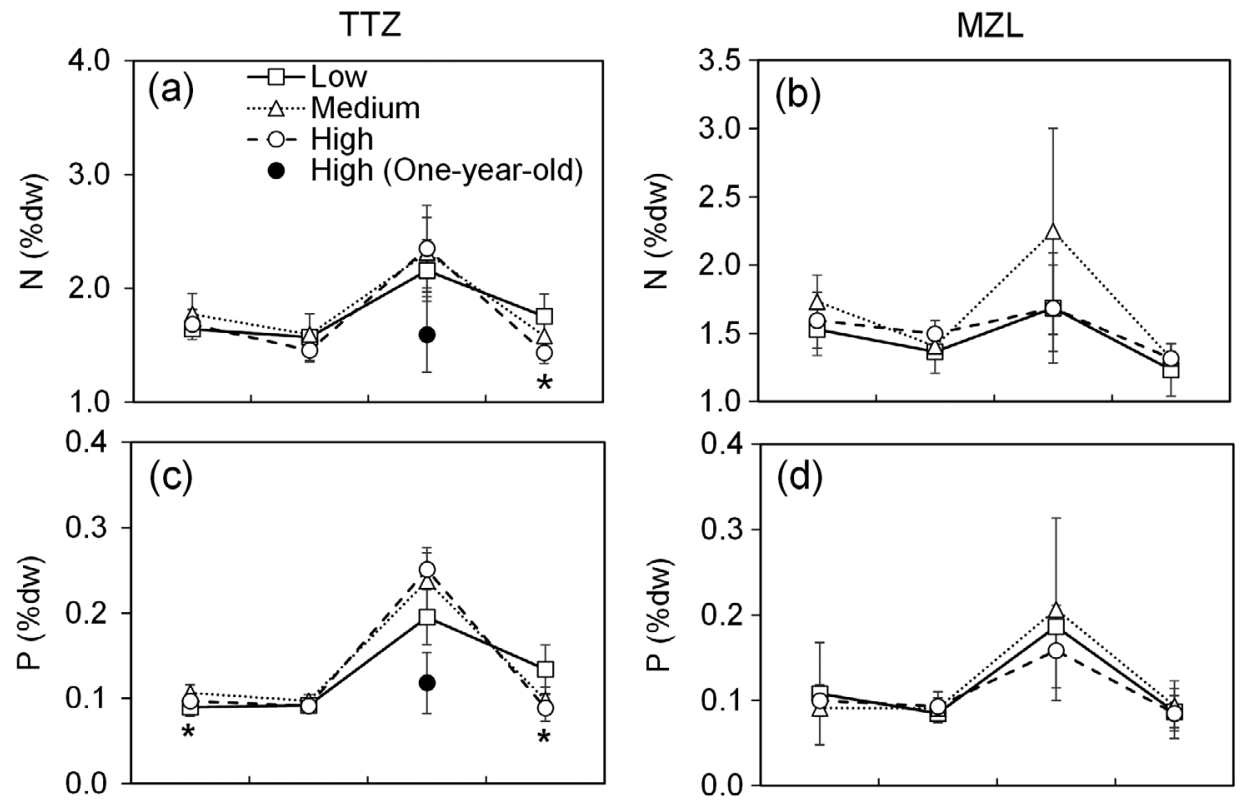

$$
0.4
$$

(d)
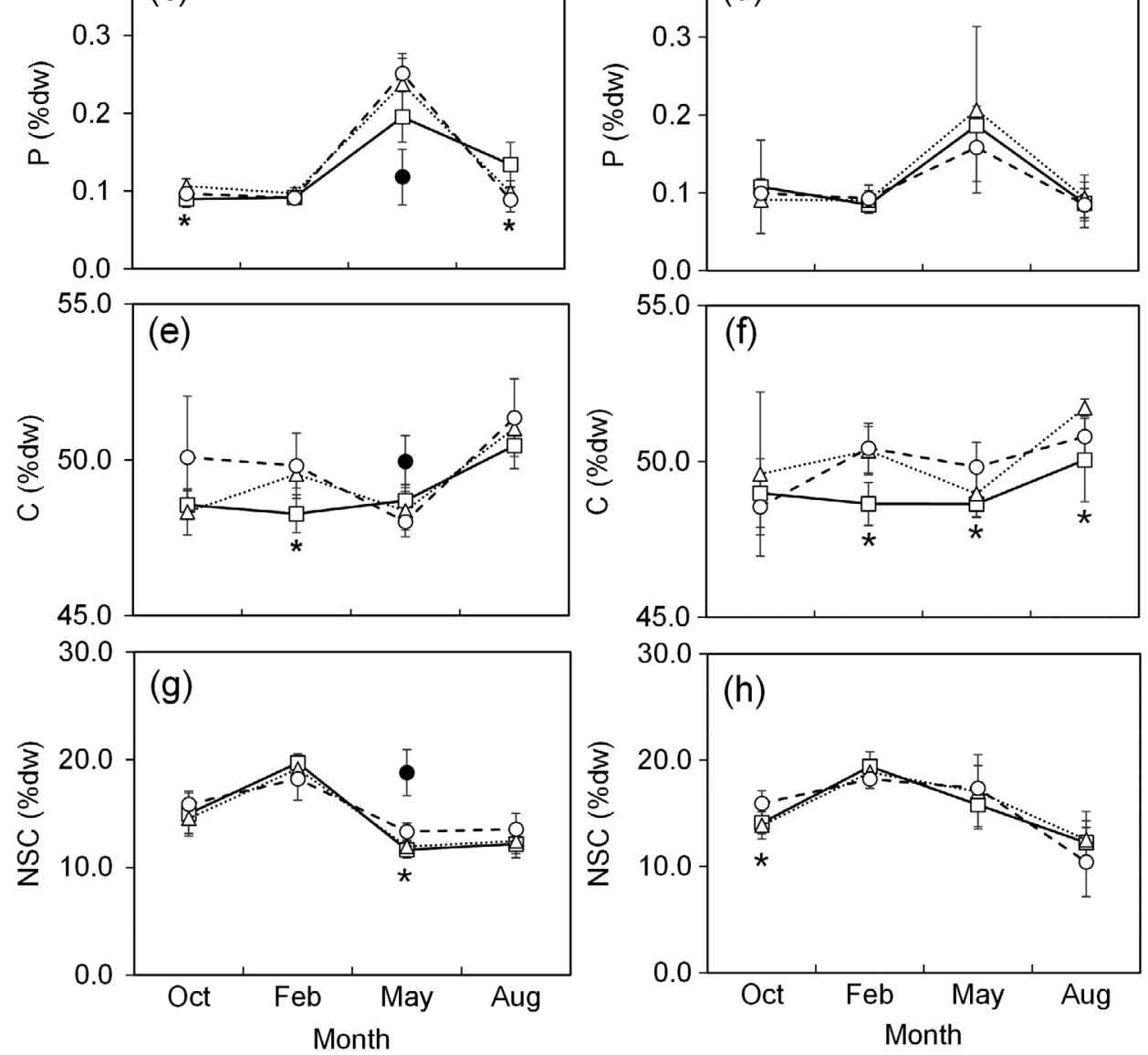

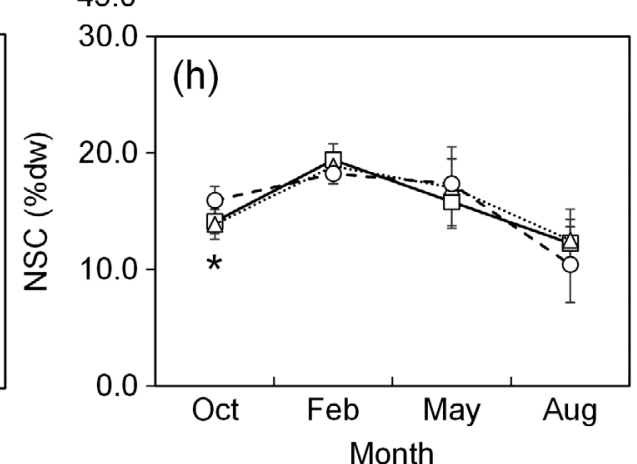

FIG URE 2 Seasonal variation of leaf C, N, P and NSC

concentration (mass-based) in Tiantangzhai transect (left panel, i.e., a, c, e, g) and Mazongling transect (right panel, i.e., b, d, f, h). Points are means of five individuals $( \pm S D)$. The $x$ axis shows the sampling month (October 2016 to August 2017). Stars indicate significant elevational effects on current-year leaves in the corresponding seasons. The differences in each chemical trait between current-year leaves and 1-year-old leaves are significant at the high elevation in TTZ transect in May. C, mass-based leaf carbon content; MZL, Mazongling transect; $\mathrm{N}$, mass-based leaf nitrogen content; NSC, mass-based leaf nonstructural carbohydrate content; $\mathrm{P}$, mass-based leaf phosphorous content; TTZ, Tiantangzhai transect

\section{2 | Variations in mature leaf traits along temperature that covaried with elevations}

Neither mass-based nor area-based leaf $\mathrm{N}$ content had linear associations with temperature. While mass-based leaf $\mathrm{N}$ content was the highest at the plot with highest CMT (Figure 4a), the area-based leaf $\mathrm{N}$ content showed the opposite with the highest value was the plot with lowest CMT (Figure 5a). There was a positive linear relationship between mass-based leaf P content and CMT, and the mass-based leaf $\mathrm{P}$ content of the plot with the highest CMT of $3.4^{\circ} \mathrm{C}$ was significantly higher than the plots with lower CMT of 2.3 and $1.7^{\circ} \mathrm{C}$ (Figure $4 \mathrm{~b}$ ), while the area-based leaf $\mathrm{P}$ content showed no variations along the temperature gradient (Figure $5 \mathrm{~b}$ ). The mass-based leaf $\mathrm{C}$ content showed no variations along the temperature gradient (Figure 4c), while the area-based leaf $C$ content was negatively related with temperature and the area-based leaf $\mathrm{C}$ content of the plot with the lowest CMT of $1.3^{\circ} \mathrm{C}$ was higher than the plots with CMT more than $2.3^{\circ} \mathrm{C}$ (Figure $5 \mathrm{c}$ ). No significantly linear relationships were found for leaf NSC content expressed on a mass basis or area basis. No differences of mass-based leaf NSC content were found between any two plots (Figure 4d), while area-based leaf NSC content of the plot with lowest CMT was higher than the plot with highest CMT (Figure 5d). LMA showed a significantly negative 
F I G U RE 3 Seasonal variation of leaf C, N, P stoichiometric characteristics in Tiantangzhai transect (left panel, i.e., a, c, e) and Mazongling transect (right panel, i.e., b, d, f). Points are means of five individuals $( \pm S D)$. The $x$ axis shows the sampling month (October 2016 to August 2017). Stars indicate significant elevational effects on current-year leaves in the corresponding seasons. The differences in each chemical trait between current-year leaves and 1-year-old leaves are significant at the high elevation in TTZ transect in May. $\mathrm{C} / \mathrm{N}$, leaf carbon to nitrogen ratio; $\mathrm{C} / \mathrm{P}$, leaf carbon to phosphorus ratio; MZL, Mazongling transect; N/P, leaf nitrogen to phosphorus ratio; TTZ,

Tiantangzhai transect
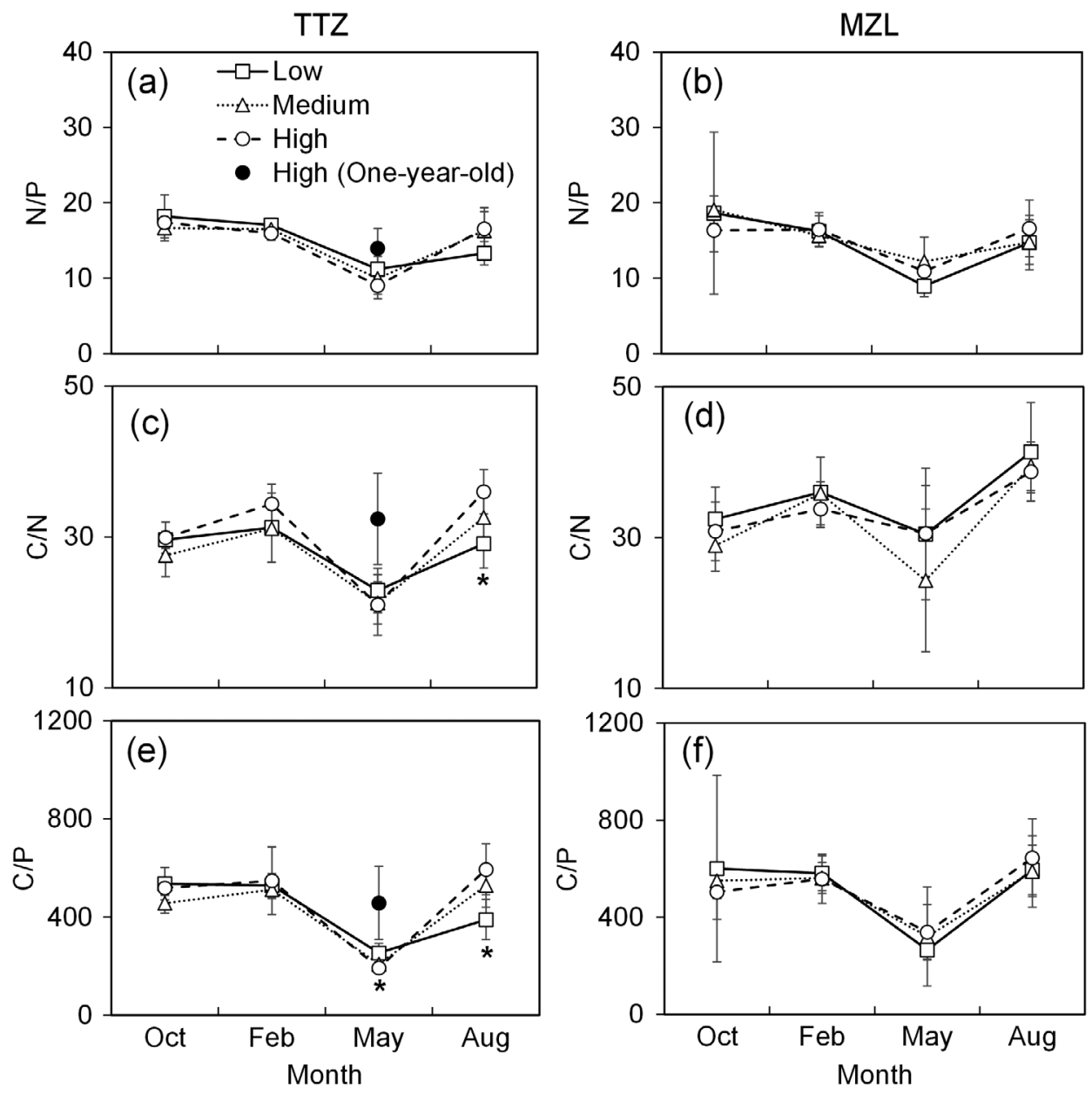

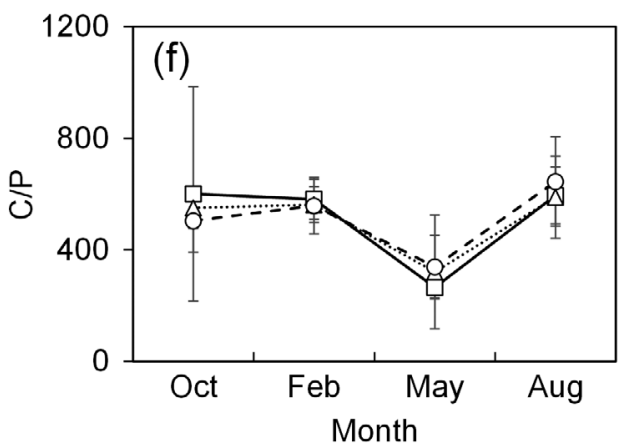

linearity with CMT and LMA of the plot with lowest CMT was significantly higher than the plots with two highest CMT (Figure 4h).

Although N/P showed an increasing trend with decreasing temperature, there were no significant differences observed among plots (Figure $4 \mathrm{~g}$ ). C/P also showed a similar linear trend and $\mathrm{C} / \mathrm{P}$ of the plot with lower $\mathrm{CMT}$ of $1.7^{\circ} \mathrm{C}$ was significantly higher than the plot with $\mathrm{CMT}$ of $3.4^{\circ} \mathrm{C}$ (Figure $4 \mathrm{f}$ ). $\mathrm{C} / \mathrm{N}$ showed no clearly linear trend with temperature, whereas $\mathrm{C} / \mathrm{N}$ of the plot with highest CMT of $3.4^{\circ} \mathrm{C}$ was lower than the plots with CMT of $1.7-2.3^{\circ} \mathrm{C}$ (Figure $4 \mathrm{e}$ ).

\section{4 | DISCUSSION}

This study showed mass-based leaf NSC content of $C$. gracilis varied with seasonality and generally reached the highest levels in the coldest period (winter) in subtropical EBLF. The seasonal variations of NSC in leaves could be partly attributed to leaf ontogeny, that is, older leaves having high NSC (Figure 2). However, a study in the Tibetan Plateau Climate Zone recorded that NSC content of both current-year leaves and previous year leaves showed significant seasonal variations and an increasing trend toward winter in another evergreen oak (Quercus aquifolioides) (Zhu et al., 2012), suggesting increasing leaf NSC toward winter could also relate with seasonal winter climate. In contrast, in tropical climate zones, with high temperatures year-round, the NSC content of evergreen broadleaved trees were mainly driven by the seasonality of precipitation (Würth, Peláez-Riedl, Wright, \& Körner, 2005). Some mediterranean sclerophyllous EBLF species (Pistacia lentiscus, Olea europaea, Arbutus andrachne and Quercus coccifera) showed similar seasonal trends, with a seasonal maximum mass-based NSC in leaves and branches at the end of winter, which was still in the cold period (Körner, 2003b), even though they undergo one more adverse period for growth (drought) than subtropical EBLF. Therefore, leaf NSC content of EBLF trees in the regions where there were considerable seasonal changes in temperature, reached the highest levels during winter in general. In other words, the seasonal variations in leaf NSC content were linked to seasonal variations in climate. 


\begin{tabular}{|c|c|c|c|c|c|c|}
\hline \multirow[b]{2}{*}{ Leaf traits } & \multirow[b]{2}{*}{ Factors } & \multirow[b]{2}{*}{$d f$} & \multicolumn{2}{|c|}{ Tiantangzhai transect } & \multicolumn{2}{|c|}{ Mazongling transect } \\
\hline & & & $\boldsymbol{F}$ & $\boldsymbol{p}$ & $\boldsymbol{F}$ & $p$ \\
\hline \multirow[t]{3}{*}{$\mathrm{N}$} & Elevations(E) & 2 & 0.8 & .435 & 2.8 & .072 \\
\hline & Seasons(S) & 3 & 40.1 & $<.001$ & 10.8 & $<.001$ \\
\hline & $\mathrm{E} \times \mathrm{S}$ & 6 & 1.5 & .202 & 1.3 & .277 \\
\hline \multirow[t]{3}{*}{$\mathrm{P}$} & Elevations(E) & 2 & 0.7 & .494 & 0.1 & .900 \\
\hline & Seasons(S) & 3 & 155.6 & $<.001$ & 16.8 & $<.001$ \\
\hline & $\mathrm{E} \times \mathrm{S}$ & 6 & 6.2 & $<.001$ & 0.3 & .954 \\
\hline \multirow[t]{3}{*}{$\mathrm{C}$} & Elevations(E) & 2 & 4.1 & .022 & 5.2 & .009 \\
\hline & Seasons(S) & 3 & 22.5 & $<.001$ & 8.7 & $<.001$ \\
\hline & $\mathrm{E} \times \mathrm{S}$ & 6 & 2.5 & .035 & 1.5 & .189 \\
\hline \multirow[t]{3}{*}{ NSC } & Elevations(E) & 2 & 1.7 & .185 & 0.0 & .961 \\
\hline & Seasons(S) & 3 & 83.5 & $<.001$ & 33.3 & $<.001$ \\
\hline & $\mathrm{E} \times \mathrm{S}$ & 6 & 1.7 & .137 & 1.4 & .222 \\
\hline \multirow[t]{3}{*}{$\mathrm{N} / \mathrm{P}$} & Elevations(E) & 2 & 0.1 & .938 & 1.0 & .388 \\
\hline & Seasons(S) & 3 & 43.6 & $<.001$ & 10.7 & $<.001$ \\
\hline & $\mathrm{E} \times \mathrm{S}$ & 6 & 2.5 & .038 & 0.6 & .758 \\
\hline \multirow[t]{3}{*}{$\mathrm{C} / \mathrm{N}$} & Elevations(E) & 2 & 3.5 & .039 & 1.4 & .246 \\
\hline & Seasons(S) & 3 & 43.4 & $<.001$ & 13.2 & $<.001$ \\
\hline & $\mathrm{E} \times \mathrm{S}$ & 6 & 2.2 & .057 & 0.6 & .736 \\
\hline \multirow[t]{3}{*}{$\mathrm{C} / \mathrm{P}$} & Elevations(E) & 2 & 2.5 & .097 & 0.0 & .992 \\
\hline & Seasons(S) & 3 & 89.0 & $<.001$ & 10.9 & $<.001$ \\
\hline & $\mathrm{E} \times \mathrm{S}$ & 6 & 5.7 & $<.001$ & 0.3 & .923 \\
\hline
\end{tabular}

TABLE 2 Summary of two-way ANOVA show the effects of season, elevation and their interaction on current-year leaf chemical traits along the Tiantangzhai and Mazongling transects

Note: Significant results $(p<.05)$ are in bold. N, mass-based leaf nitrogen content; P, mass-based leaf phosphorous content; C, mass-based leaf carbon content; NSC, mass-based leaf nonstructural carbohydrate content; $\mathrm{N} / \mathrm{P}$, leaf nitrogen to phosphorus ratio; $\mathrm{C} / \mathrm{N}$, leaf carbon to nitrogen ratio; $\mathrm{C} / \mathrm{P}$, leaf carbon to phosphorus ratio.

Previous studies have emphasized the important role of NSC in cold tolerance mechanisms (Dietze et al., 2014). However, achieving cold tolerance by accumulating solutes is not effective if substantial frosts occur. Although NSC concentrations show a characteristic seasonal variation associated with seasonal changes in temperature, due to the limit of normal osmotic potential most plants would freeze at a temperature of $-1.8^{\circ} \mathrm{C}$ if they were under the sole protection of osmotic adjustment (Körner, 2012). Compared with trees at low elevation in this study, the trees at high elevation did not show higher concentrations of NSC and greater increases in NSC in winter, suggesting that the freezing point depression for $C$. gracilis by accumulating sugars is not a main way of achieving low temperature resistance and the individuals at upper limit must employ other strategies to adapt to colder winter temperature and longer duration of winter (Körner, 2012). Elsewhere, leaves of species at higher elevation tend to have higher LMA to enhance the adaptability with low temperature (Ball et al., 2002; Wang et al., 2017). Indeed, LMA of $C$. gracilis also significantly increased with decreasing temperature in the current study - as has been found in previous studies at intraspecific scales (González-Zurdo, Escudero, Babiano, García-Ciudad, \& Mediavilla, 2016; Read et al., 2014; Vitousek et al., 1990).

There was a strong input of nitrogen and phosphorus in the emerging leaves in spring and a decreasing trend toward summer, which is consistent with other previously studied evergreen species, that is, Arbutus unedo, $O$. europaea, P. lentiscus, Q. coccifera (Meletiou-Christou, Rhizopoulou, \& Diamantoglou, 1994), Quercus suber (Oliveira, Martins-Loução, Correia, \& Catarino, 1996; Passarinho, Lamosa, Baeta, Santos, \& Ricardo, 2006) and Quercus ilex (Palacio et al., 2018). This pattern would be mainly conditioned by the ontogeny of the leaves, due to the effect of the dilution caused by the inversion of $\mathrm{C}$ in the current year's leaves as their development progresses (Escudero, Del Arco, \& Garrido, 1992). Although the generally seasonal dynamics of leaf chemical traits were 
F I G URE 4 Variations of leaf traits (mass-based) of mature leaves along the coldest month mean temperature (CMT) gradient (mean $\pm S D$ ). The data are pooled from Tiantangzhai and Mazongling transects. Dotted line indicates a significant linear relationship. Significant differences are denoted with different lowercase letters. Hollow circles represent the plots in MZL transect, while filled circles represent the plots in TTZ transect. $\mathrm{C}$, mass-based leaf carbon content; LMA, leaf dry mass per area; MZL, Mazongling transect; $\mathrm{N}$, mass-based leaf nitrogen content; NSC, massbased leaf nonstructural carbohydrate content; P, mass-based leaf phosphorous content; TTZ, Tiantangzhai transect
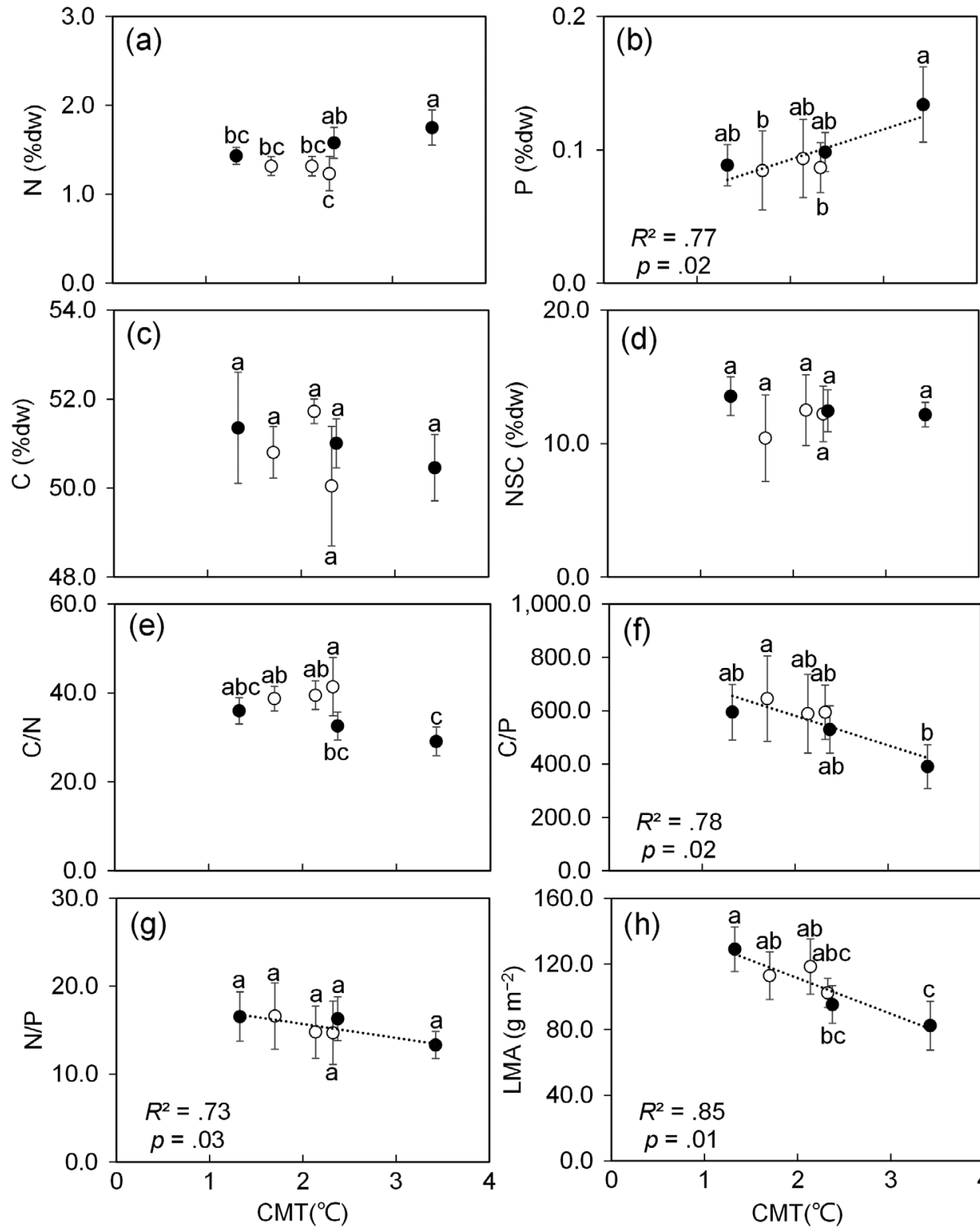

similar among elevations, there were still obvious differences between the upper limits (high elevations) and lower elevations on the TTZ transect (Figures 2 and 3). This was in line with the more pronounced interaction effects on the TTZ transect and coincided with strong climate gradients along the TTZ transect, that is, lapse rate of $0.54^{\circ} \mathrm{C}$ per $100 \mathrm{~m}$ and 24 more frost days at high than low elevation (Table 1). In contrary, climate gradients were weak on the MZL transect, that is, lapse rate of $0.15^{\circ} \mathrm{C}$ per $100 \mathrm{~m}$ and only six more frost days at high than low elevation. The phenology was more synchronized among elevations in the MZL transect, presumably because of smaller temperature differences, leading to negligible differences in leaf traits among elevations. Therefore, to minimize the effects of phenology in our study, only traits data collected in summer, when leaves were fully expanded and tree growth rate was fastest, were used to analyze the responses of leaf traits to temperature (which covaried with elevation) for the two transects.

In the current study, $\mathrm{N}$ content per area was the highest at the upper limit (Figure 5). The increase in leaf $\mathrm{N}$ content can generally be considered as an adaptation to enhance metabolic activities and growth rates under low temperature (Oleksyn et al., 1998; Weih \& Karlsson, 2001). For instance, leaf $\mathrm{N}$ content can increase photosynthetic capacity (Wright et al., 2004). While massbased leaf $\mathrm{N}$ and $\mathrm{P}$ showed contrasting trends along temperature gradients compared with the traits expressed on an area basis. This coincided with the increases in leaf $\mathrm{C}$ content per area and LMA with decreasing temperature, indicating that dilution of dry mass allocation in leaves contributed much to decrease in mass-based $\mathrm{N}$ and $\mathrm{P}$ content at higher elevations. 

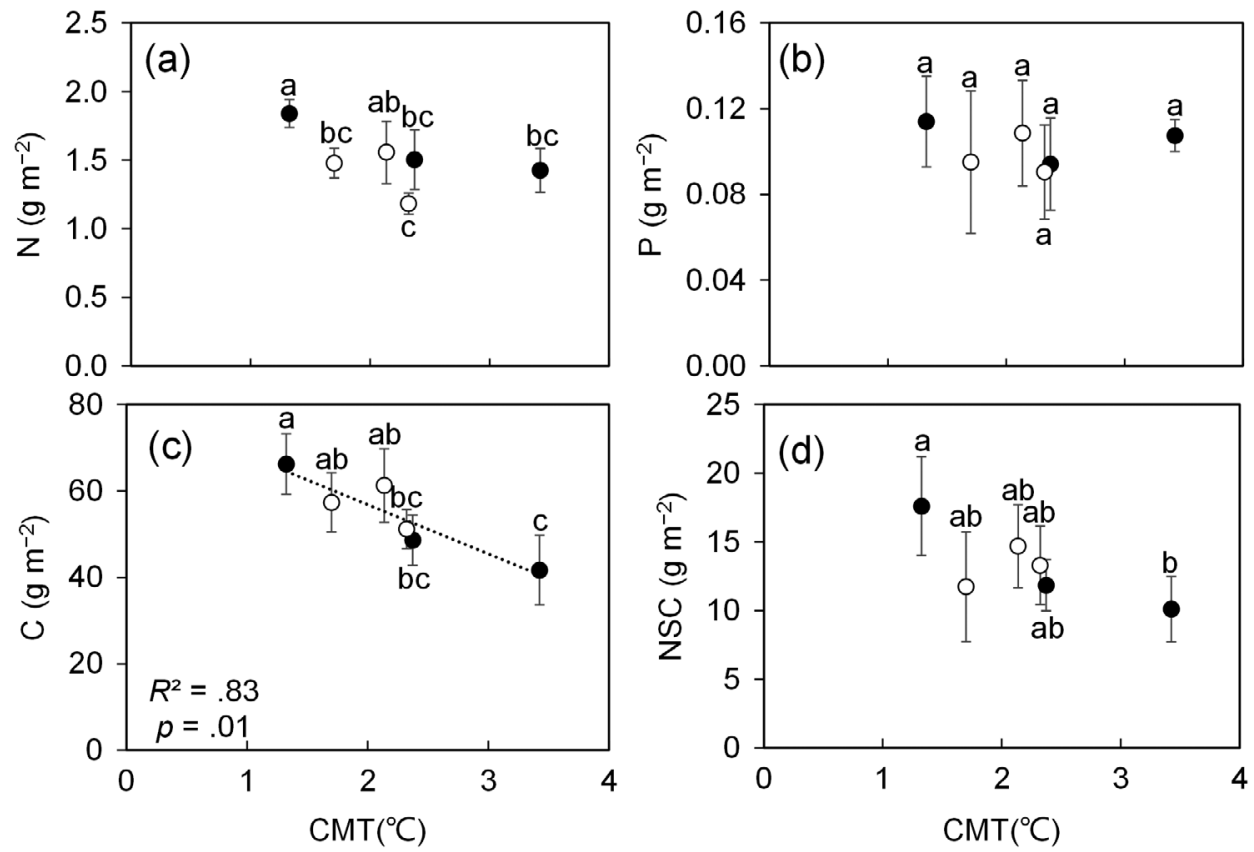

FI G URE 5 Variations of leaf chemical traits (area-based) of mature leaves along the coldest month mean temperature (CMT) gradient (mean $\pm S D$ ). The data are pooled from Tiantangzhai and Mazongling transects. Dotted line indicates a significant linear relationship. Significant differences are denoted with different lowercase letters. Hollow circles represent the plots in MZL transect, while filled circles represent the plots in TTZ transect. C, area-based leaf carbon content; MZL, Mazongling transect; $\mathrm{N}$, area-based leaf nitrogen content; NSC, area-based leaf nonstructural carbohydrate content; $\mathrm{P}$, area-based leaf phosphorous content; TTZ, Tiantangzhai transect
Although the correlations showed that there was a significantly negative correlation between soil available $\mathrm{P}$ concentration and leaf $\mathrm{N}$ concentration, and a positive correlation between soil available $\mathrm{P}$ concentration and leaf $\mathrm{C} / \mathrm{N}$ in the present study (Table S2), the soil nutritional conditions played an unimportant role in elevational variations of leaf chemical traits, since soil nutrient contents did not significantly covary with elevation (Table S1).

Although leaf N/P ratio at the plots with the two lowest CMT exceeded 16 (where N/P ratio $>16$ and $<14$ indicates a $\mathrm{P}$ and $\mathrm{N}$ limitation, respectively, Koerselman \& Meuleman, 1996), the differences were not significant among the plots. These results suggested that the growth and development of $C$. gracilis at its upper limits was not severely affected by $\mathrm{P}$ limitation compared with trees at lower elevations.

Leaf $\mathrm{C} / \mathrm{P}$ ratio showed increasing trend approaching the upper limit, as did leaf $\mathrm{C} / \mathrm{N}$ to some extent. Leaf $\mathrm{C} / \mathrm{N}$ and $\mathrm{C} / \mathrm{P}$ represent the amount of carbon assimilated per unit $\mathrm{N}$ and $\mathrm{P}$, indicating $\mathrm{N}$ and $\mathrm{P}$ use efficiency of plants (Chapin, 1980; Li et al., 2017). Hence, C. gracilis enhanced the $\mathrm{N}$ and $\mathrm{P}$ use efficiency at high elevation. These strategies may be associated with longer leaf longevity for evergreen leaves at colder sites (Wright et al., 2005). Leaf longevity was outside the scope of the current study, but also positively correlates with LMA (Wright et al., 2004) and enhanced nutrients use efficiency (Small, 1972). These relationships between traits and strategies for evergreen trees in (sub)tropical regions warrant further investigation.

\section{5 | CONCLUSIONS}

Overall, our study indicated that the individuals of $C$. gracilis at the upper limits possessed greater LMA and higher nutrient use efficiency. Although the foliar NSC contents across elevations showed no significant differences in winter, the NSC content reached the highest value in winter across the seasons. Together these responses could help $C$. gracilis to cope with low-temperature stresses at its upper distributional limits. For unifying theories on the strategies of trees to deal with such stresses, and how they may be affected by global climatic changes, more similar data on broadleaved evergreen species in tropical and subtropical areas is required.

\section{ACKNOWLEDGMENTS}

The authors thank Aicui Tu, Lingling Jin, Zuhua Song for invaluable help with fieldwork in Dabie mountains. Our gratitude also goes to Tianpin Ni for leaf grinding and Lingling Jin, Beijia Qin for measuring leaf chemical traits. This study was funded by the National Natural Science Foundation of China (31500355, 31670438 and 31600343).

\section{ORCID}

Xi Jin Zhang (1) https://orcid.org/0000-0003-0399-7857

\section{REFERENCES}

Atkin, O. K., Botman, B., \& Lambers, H. (1996). The causes of inherently slow growth in alpine plants: An analysis based on the underlying carbon economies of alpine and lowland Poa species. Functional Ecology, 10, 698-707. 
Ball, M. C., Wolfe, J., Canny, M., Hofmann, M., Nicotra, A. B., \& Hughes, D. (2002). Space and time dependence of temperature and freezing in evergreen leaves. Functional Plant Biology, 29, $1259-1272$.

Buysse, J., \& Merckx, R. (1993). An improved colorimetric method to quantify sugar content of plant tissue. Journal of Experimental Botany, 44, 1627-1629.

Chai, Y., Zhang, X., Yue, M., Liu, X., Li, Q., Shang, H., ... Zhang, R. (2015). Leaf traits suggest different ecological strategies for two Quercus species along an altitudinal gradient in the Qinling Mountains. Journal of Forest Research, 20, 501-513.

Chapin, F. S. (1980). The mineral nutrition of wild plants. Annual Review of Ecology and Systematics, 11, 233-260.

Cordell, S., Goldstein, G., Meinzer, F. C., \& Handley, L. L. (1999). Allocation of nitrogen and carbon in leaves of Metrosideros polymorpha regulates carboxylation capacity and $\delta 13 \mathrm{C}$ along an altitudinal gradient. Functional Ecology, 13, 811-818.

Da, L., Kang, M., Song, K., Shang, K., Yang, Y., Xia, A., \& Qi, Y. (2009). Altitudinal zonation of human-disturbed vegetation on Mt. Tianmu, eastern China. Ecological Research, 24, 1287-1299.

Dietze, M. C., Sala, A., Carbone, M. S., Czimczik, C. I., Mantooth, J. A., Richardson, A. D., \& Vargas, R. (2014). Nonstructural carbon in woody plants. Annual Review of Plant Biology, 65, 667-687.

Escudero, A., Del Arco, J. M., \& Garrido, M. V. (1992). The efficiency of nitrogen retranslocation from leaf biomass in Quercus ilex ecosystems. Vegetatio, 99, 225-237.

Fang, J., Wang, Z., \& Tang, Z. (2011). Atlas of woody plants in China: Distribution and Climate. Berlin, Germany: Springer.

Fox, J., \& Weisberg, S. (2019). An $\{R\}$ companion to applied regression (3rd ed.). Thousand Oaks, CA: Sage Retrieved from https://socialsciences.mcmaster.ca/jfox/Books/Companion/

González-Zurdo, P., Escudero, A., Babiano, J., García-Ciudad, A., \& Mediavilla, S. (2016). Costs of leaf reinforcement in response to winter cold in evergreen species. Tree Physiology, 36, 273-286.

Klich, M. G. (2000). Leaf variations in Elaeagnus angustifolia related to environmental heterogeneity. Environmental and Experimental Botany, 44, 171-183.

Koerselman, W., \& Meuleman, A. F. (1996). The vegetation N:P ratio: A new tool to detect the nature of nutrient limitation. Journal of Applied Ecology, 33, 1441-1450.

Körner, C. (2003a). Alpine plant life-Functional plant ecology of high mountain ecosystems. Berlin, Germany: Springer.

Körner, C. (2003b). Carbon limitation in trees. Journal of Ecology, 91, 4-17.

Körner, C., Neumayer, M., Menendez-Riedl, S. P., \& SmeetsScheel, A. (1989). Functional morphology of mountain plants. Flora, 182, 353-383.

Körner, C. (2012). Alpine treelines: Functional ecology of the global high elevation tree limits. Basel, Switzerland: Springer.

Kubacka-Zębalska, M., \& Kacperska, A. (1999). Low temperatureinduced modifications of cell wall content and polysaccharide composition in leaves of winter oilseed rape (Brassica napus $\mathrm{L}$. var. oleifera L.). Plant Science, 148, 59-67.

Li, C., Zhang, X., Liu, X., Luukkanen, O., \& Berninger, F. (2006). Leaf morphological and physiological responses of Quercus aquifolioides along an altitudinal gradient. Silva Fennica, 40, 5-13.
Li, H., Crabbe, M. J. C., Xu, F., Wang, W., Ma, L., Niu, R., ... Ma, X. (2017). Seasonal variations in carbon, nitrogen and phosphorus concentrations and C:N:P stoichiometry in different organs of a Larix principis-rupprechtii Mayr. Plantation in the Qinling Mountains, China. PLoS One, 12, e185163.

Mayor, J. R., Sanders, N. J., Classen, A. T., Bardgett, R. D., Clément, J., Fajardo, A., ... Chisholm, C. (2017). Elevation alters ecosystem properties across temperate treelines globally. Nature, 542, 91-95.

Mediavilla, S., Gallardo-López, V., González-Zurdo, P., \& Escudero, A. (2012). Patterns of leaf morphology and leaf $\mathrm{N}$ content in relation to winter temperatures in three evergreen tree species. International Journal of Biometeorology, 56, 915-926.

Meletiou-Christou, M. S., Rhizopoulou, S., \& Diamantoglou, S. (1994). Seasonal changes of carbohydrates, lipids and nitrogen content in sun and shade leaves from four Mediterranean evergreen sclerophylls. Environmental and Experimental Botany, 34, 129-140.

Mendiburu F. D. (2019). agricolae: Statistical procedures for agricultural research. R package version 1.3-1. Retrieved from https:// CRAN.R-project.org/package $=$ agricolae

Midolo, G., De Frenne, P., Hölzel, N., \& Wellstein, C. (2019). Global patterns of intraspecific leaf trait responses to elevation. Global Change Biology, 7, 2485-2498.

Morin, X., Améglio, T., Ahas, R., Kurz-Besson, C., Lanta, V., Lebourgeois, F., ... Chuine, I. (2007). Variation in cold hardiness and carbohydrate concentration from dormancy induction to bud burst among provenances of three European oak species. Tree Physiology, 27, 817-825.

Niinemets, Ü. (2016). Does the touch of cold make evergreen leaves tougher? Tree Physiology, 36, 267-272.

Nitta, I., \& Ohsawa, M. (1997). Leaf dynamics and shoot phenology of eleven warm-temperate evergreen broad-leaved trees near their northern limit in Central Japan. Plant Ecology, 130, 71-88.

Ohsawa, M. (1990). An interpretation of latitudinal patterns of forest limits in south and east Asian mountains. Journal of Ecology, 78, 326-339.

Oleksyn, J., Modrzýnski, J., Tjoelker, M. G., Reich, P. B., \& Karolewski, P. (1998). Growth and physiology of Picea abies populations from elevational transects: Common garden evidence for altitudinal ecotypes and cold adaptation. Functional Ecology, 12, 573-590.

Oliveira, G., Martins-Loução, M. A., Correia, O., \& Catarino, F. (1996). Nutrient dynamics in crown tissues of cork-oak (Quercus suber L.). Trees, 10, 247-254.

Palacio, S., Camarero, J. J., Maestro, M., Alla, A. Q., Lahoz, E., \& Montserrat-Martí, G. (2018). Are storage and tree growth related? Seasonal nutrient and carbohydrate dynamics in evergreen and deciduous Mediterranean oaks. Trees, 32, 777-790.

Passarinho, J. A., Lamosa, P., Baeta, J. P., Santos, H., \& Ricardo, C. P. (2006). Annual changes in the concentration of minerals and organic compounds of Quercus suber leaves. Physiologia Plantarum, 127, 100-110.

Rathore, N., Thakur, D., \& Chawla, A. (2018). Seasonal variations coupled with elevation gradient drives significant changes in eco-physiological and biogeochemical traits of a high altitude 
evergreen broadleaf shrub, Rhododendron anthopogon. Plant Physiology and Biochemistry, 132, 708-719.

Read, Q. D., Moorhead, L. C., Swenson, N. G., Bailey, J. K., \& Sanders, N. J. (2014). Convergent effects of elevation on functional leaf traits within and among species. Functional Ecology, $28,37-45$.

Schneider, C. A., Rasband, W. S., \& Eliceiri, K. W. (2012). NIH Image to ImageJ: 25 years of image analysis. Nature Methods, 9, 671-675.

Shi, P., Körner, C., \& Hoch, G. (2010). A test of the growth-limitation theory for alpine tree line formation in evergreen and deciduous taxa of the eastern Himalayas. Functional Ecology, 22, 213-220.

Small, E. (1972). Photosynthetic rates in relation to nitrogen recycling as an adaptation to nutrient deficiency in peat bog plants. Canadian Journal of Botany, 50, 2227-2233.

Song, K., \& Da, L. (2016). Evergreen-deciduous broad-leaved forest ecotone in eastern China: Retrospect and new perspectives. In Vegetation structure and function at multiple spatial, temporal and conceptual scales (pp. 129-147). Cham, Switzerland: Springer.

Song, K., Kohyama, T. S., \& Da, L. J. (2014). Transition patterns across an evergreen-deciduous broad-leaved forest ecotone: The effect of topographies. Journal of Vegetation Science, 25, 1257-1266.

Song, Y. (1988). The essential characteristics and main types of the broad-leaved evergreen forest in China. Phytocoenologia, 16, 105-123.

Stefanowska, M., Kuraś, M., Kubacka-Zebalska, M., \& Kacperska, A. (1999). Low temperature affects pattern of leaf growth and structure of cell walls in winter oilseed rape (Brassica napus L., var. oleifera L.). Annals of Botany, 84, 313-319.

Vitousek, P. M., Field, C. B., \& Matson, P. A. (1990). Variation in foliar $\delta^{13} \mathrm{C}$ in Hawaiian Metrosideros polymorpha: A case of internal resistance? Oecologia, 84, 362-370.

Wang, M., Liu, G., Jin, T., Li, Z., Gong, L., Wang, H., \& Ye, X. (2017). Age-related changes of leaf traits and stoichiometry in an alpine shrub (Rhododendron agglutinatum) along altitudinal gradient. Journal of Mountain Science, 14, 106-118.

Weih, M., \& Karlsson, P. S. (2001). Growth response of mountain birch to air and soil temperature: Is increasing leaf-nitrogen content an acclimation to lower air temperature? New Phytologist, 150, 147-155.

Woodward, F. I. (1979). The differential temperature responses of the growth of certain plant species from different altitudes. II. Analyses of the control and morphology of leaf extension and specific leaf area of Phleum bertolonii D.C. and P. alpinum L. New Phytologist, 82, 397-405.

Wright, I. J., Reich, P. B., Cornelissen, J. H., Falster, D. S., Groom, P. K., Hikosaka, K., ... Oleksyn, J. (2005). Modulation of leaf economic traits and trait relationships by climate. Global Ecology and Biogeography, 14, 411-421.

Wright, I. J., Reich, P. B., Westoby, M., Ackerly, D. D., Baruch, Z., Bongers, F., ... Diemer, M. (2004). The worldwide leaf economics spectrum. Nature, 428, 821-827.

Würth, M. K. R., Peláez-Riedl, S., Wright, S. J., \& Körner, C. (2005). Non-structural carbohydrate pools in a tropical forest. Oecologia, 143, 11-24.

Xu, F., Guo, W., Xu, W., Wei, Y., \& Wang, R. (2009). Leaf morphology correlates with water and light availability: What consequences for simple and compound leaves? Progress in Natural Science, 19, 1789-1798.

Xue, L., Zhang, R., Xi, R., Guo, S., Yang, Z., Liu, B., \& Wei, R. (2012). Seasonal change of leaf morphological traits of six broadleaf seedlings in South China. Acta Ecologica Sinica, 32, 123-134 (in Chinese).

Yim, Y., \& Kira, T. (1975). Distribution of forest vegetation and climate in the Korean peninsula: I. Distribution of some indices of thermal climate. Japanese Journal of Ecology, 25, 77-88.

Zhang, S. B., Zhang, J. L., Slik, J. F., \& Cao, K. F. (2012). Leaf element concentrations of terrestrial plants across China are influenced by taxonomy and the environment. Global Ecology and Biogeography, 21, 809-818.

Zhu, W., Cao, M., Wang, S., Xiao, W., \& Li, M. (2012). Seasonal dynamics of mobile carbon supply in Quercus aquifolioides at the upper elevational limit. PLoS One, 7, e34213.

\section{SUPPORTING INFORMATION}

Additional supporting information may be found online in the Supporting Information section at the end of this article.

How to cite this article: Zhang XJ, Song $\mathrm{K}$, Pan YJ, et al. Responses of leaf traits to low temperature in an evergreen oak at its upper limit. Ecological Research. 2020;1-12. https://doi.org/10. $\underline{1111 / 1440-1703.12157}$ 